This item was submitted to Loughborough's Research Repository by the author.

Items in Figshare are protected by copyright, with all rights reserved, unless otherwise indicated.

\title{
The design of next generation in-vehicle navigation systems for the older
} driver

PLEASE CITE THE PUBLISHED VERSION

PUBLISHER

(C) Elsevier

LICENCE

CC BY-NC-ND 4.0

REPOSITORY RECORD

May, Andrew, Tracy Ross, and Zaheer Osman. 2019. "The Design of Next Generation In-vehicle Navigation Systems for the Older Driver". figshare. https://hdl.handle.net/2134/665. 
The design of next generation in-vehicle navigation systems for the older driver

Andrew May ${ }^{\mathrm{a}}$ (corresponding author)

Tracy Ross ${ }^{\mathrm{a}}$, and Zaheer Osman ${ }^{\mathrm{a}}$

${ }^{a}$ Ergonomics and Safety Research Institute, Loughborough University

Loughborough, LE11 3UZ, UK

Contact details for corresponding author:

Email: a.j.may@lboro.ac.uk

fax: +44 (0)1509 226960

\begin{abstract}
It has been proposed that the current design of in-vehicle displays may not be appropriate for the older driver. This paper describes an empirical, road-based investigation of the benefits to older and younger drivers of providing landmarks within the instructions presented by an in-vehicle navigation system. Thirty two participants navigated a challenging urban route using either landmarks or distance information to identify the location of forthcoming manoeuvres. A range of driver behaviour measures were collected, including visual glance data, driving errors, driver workload, navigation errors, navigation confidence, and pre and post-trial driver attitudinal responses. Results show that, for older and younger drivers, landmarks reduced the time spent glancing to a visual display, reduced navigation and driving errors, and influenced driver confidence. There were some key differences between the older and younger drivers. The wider implications for the design of in-car interfaces for the older driver are discussed.
\end{abstract}

Keywords

Older Driver, Vehicle Navigation, Landmarks, Interface Design, Driver Performance 
The design of next generation in-vehicle navigation systems for the older driver

\section{Introduction}

With the widely forecast increase in the number of older drivers over the next 20 years, it is recognised that particular care must be taken with the design of in-vehicle human-machine interfaces (HMIs) (Pauzie, 2003; Widlroither, Hagenmeyer, Breker, \& Panou, 2003). Although there are design challenges, the introduction of new technologies such as navigation systems in the vehicle also presents opportunities for adding value for this segment of the population.

Navigation is identified as a key activity for maintaining the mobility and hence independence and quality of life of the older population (Burns, 1997; Goodman, Brewster, \& Gray, 2005). Research has long shown that drivers have difficulties in planning and following efficient routes (King, 1986; Streeter, 1986; Wierwille, Antin, Dingus, \& Hulse, 1989). Older drivers may find navigation particularly difficult due to degradation of their cognitive, perceptual and motor skills (Dingus et al., 1997; Kirasic, 2000). Older drivers also perceive wayfinding as more difficult than younger drivers (Burns, 1997). (Note: the term 'navigation' is used in this paper in preference to 'wayfinding', although 'wayfinding' more accurately describes the dynamic step by step decision making process (Passini, 1984) of a driver using a navigation system to reach a destination. )

In-vehicle navigation systems offer a technological solution to driver navigation in an unfamiliar area. They typically present real-time navigation information to the driver based on a series of map overviews and/or turn-by-turn instructions via visual (graphics and text) and auditory (verbal and non-verbal) modalities.

A potential safety concern with in-vehicle navigation systems is their use of relatively complex visual displays. (Mourant, Tsai, Al-Shihabi, \& Jaeger, 2001) suggest that the use of in-vehicle displays, in their present configuration, is not appropriate for older drivers. As a consequence of the increase in older drivers, the user-centred design of automotive humanmachine interfaces (HMIs), including navigation systems, is becoming critically important (Pauzie, 2003; Widlroither et al., 2003). Several authors have highlighted the potential for the incorporation of landmark information as navigation cues to increase the effectiveness and safety of future navigation systems, a recent example being the review by (Burnett, 2000). Landmarks are key elements in a piloting strategy to an unfamiliar destination (Allen, 1999), as typically supported by a vehicle navigation system. By providing external reference points 
which are easily remembered and recognised, they can potentially reduce the need to refer to an in-vehicle display in order to locate a forthcoming turn.

The potential benefits of landmarks are relatively well established. A range of studies has empirically demonstrated how landmarks have the potential to enhance driver navigation systems in terms of: (1) effective navigation decisions (Tom \& Denis, 2003); (Jackson, 1998); (Bengler, Haller, \& Zimmer, 1994); (2) reduced cognitive effort and distraction (Burnett, 1998), and (3) increased confidence and satisfaction (Alm, Nilsson, Jarmark, Savelid, \& Hennings, 1992; Green, Hoekstra, Williams, Wen, \& George, 1993).

(Dingus et al., 1997) has shown that although older drivers had difficulty driving and navigating simultaneously, and made more safety-related errors than younger drivers, they also benefited considerably from a well designed HMI. (Goodman et al., 2005), describing a pedestrian context, has shown landmarks to be particularly useful for navigation by the older population.

The aim of the study reported in this article was to investigate, within a real driving environment, the extent to which older drivers benefited from the provision of landmarks within navigation instructions. Two key benchmark comparisons were used: (1) older driver performance with and without landmarks, and (2) older driver performance with landmarks compared to younger drivers using those same landmarks for navigation purposes.

\section{Landmarks for vehicular navigation}

(Kaplan, 1976) defined a landmark as "a known place for which the individual has a well formed representation”. (Lynch, 1960) described them as external reference points which are easily observable from a distance. Several studies have commented on the characteristics of landmarks that are useful for navigation purposes. (Burnett, Smith, \& May, 2001) identified 5 attributes that were characteristic of 'good' landmarks for vehicular navigation: permanence, visibility, usefulness of location, uniqueness/distinctiveness, and their ability to be described with brevity. (Green, Levison, Paelke, \& Serafin, 1995) state that the best landmarks are those which can be seen from a distance, are close to the road, near junctions, and permanent.

The landmarks incorporated within this study were traffic lights, pedestrian lights, a petrol station and a distinctive public house. They would all be termed effective landmarks, since they were familiar, permanent objects, unique (ie dissimilar to other nearby objects), usefully located (at or within 20m of a manoeuvre) and visible and recognisable to an approaching driver at a mean distance of $210 \mathrm{~m}$ based on an independent ratings process. 


\section{Method}

\subsection{Apparatus}

A Land Rover Freelander ${ }^{\mathrm{TM}}$, fitted with a state of the art, DVD-based satellite navigation system, was used to provide visual and verbal turn instructions, to enable a driver to navigate a route. On approach to each of the manoeuvres en-route, the satellite navigation system displayed a direction arrow integrated into a simplified junction overview and also incorporated a distance countdown bar that showed the distance to the turn (starting at 500 metres and counting down to zero in $50 \mathrm{~m}$ increments), the name of the current road and the name of the road being turned into. In between manoeuvres, the visual display presented a map overview to the driver.

In order to simulate the provision of landmark information to the driver, auditory prompts were recorded that either included landmarks or distance to turn information. Available landmarks at each manoeuvre were assessed in terms of the main attributes discussed above as those which determine their suitability (quality in use) for navigation purposes: visibility, familiarity, uniqueness and location, and potentially effective landmarks were chosen accordingly.

The recorded auditory messages were triggered and played to the driver in lieu of the auditory output generated automatically by the navigation system. This, in conjunction with the visual display generated by the navigation system, enabled participants to navigate the trial route. The messages consisted of up to three verbal prompts. A Preview 1 message was given at $500 \mathrm{~m}$ or after the completion of a prior manoeuvre if this was less than $500 \mathrm{~m}$ from the approaching manoeuvre. This Preview 1 message was omitted if there was less than 300 m between manoeuvres. A Preview 2 message was given at $200 \mathrm{~m}$ or after the completion of a prior manoeuvre as above. A Final auditory tone (beep) was given at $50 \mathrm{~m}$ to the manoeuvre. A typical auditory message that included a landmark was 'turn right after the Texaco $^{\mathrm{TM}}$ petrol station', i.e. it included no distance-to-turn information.

To ensure face validity throughout the trial, where landmarks were present at incidental (ie non-target) manoeuvres, they were presented to the driver at these locations, but these data were not analysed. Where landmarks were not present at incidental manoeuvres, verbal distance to turn information was given for all participants.

\subsection{Participants}

Thirty two participants, recruited from the general public via web notice boards, local newspaper advertisements and posters took part in the trial. They were divided into two age 
categories: younger drivers (aged 21 - 40) and older drivers (aged 55 and over). They all satisfied the following criteria: self-reported normal or corrected-to normal vision; clean driving licence, regular drivers for least the last three years; had not previously used a navigation system; were unfamiliar with the area where the study took place. A pre-screening exercise also enabled potential participants to be balanced for gender and navigation ability which have been shown to potentially influence navigation performance, driving behaviour and/or information preferences (Burns, 1998); (Ward, 1986), (Allerton, 2000; Streeter, 1986). In addition, participants were also matched on self-reported distance judgment ability, since this skill was fundamental in interpreting the distance countdown bar on the display, has been shown to vary considerably within the population (Fine \& Kobrick, 1983), and be negatively impacted by concurrent task demands (Boeoek \& Gaerling, 1978). Participants were then randomly allocated to one of the between-subjects experimental conditions. On completion of the trial they were paid $£ 20$ for their participation.

\subsection{Experimental route}

An experimental route was chosen based around the south of Leicester, a city in the UK with approximately 320,000 inhabitants. This route was explicitly designed to be navigationally challenging, having 37 driver decision points within its $17.5 \mathrm{~km}$ length. A driver decision point was defined as (1) a location where a driver had more than one navigation option and was not following a single major traffic flow, or (2) had to potentially stop or give way to other traffic. In practice, these were locations where a lack of navigation information could result in a navigation error from a driver, or navigation uncertainty on their behalf. The route was an urban/suburban route comprising 10\% dual carriageway and $90 \%$ single carriageway. Approximately 75\% was residential housing, 25\% being urban (but not city centre) retail/commercial. The route took approximately 40 minutes to drive, the speed limit on the majority of the route being $50 \mathrm{kph}$. The route included eight target manoeuvres which were defined according to the criteria shown in Table 1.

\section{$<$ INSERT TABLE 1 ABOUT HERE $>$}

In addition to the eight target manoeuvres, there were 25 manoeuvres en-route which were incidental and merely served to link the target manoeuvres into a continuous circuit. There were four manoeuvres where data was not collected due to operational constraints. Participants were unaware that there were target and non-target manoeuvres. 


\subsection{Experimental Design}

The experimental design was a 2 (Age) x 2 (Information) x 8 (Manoeuvre) mixed design. Age was a between-subjects factor, (50\% aged $21-40 ; 50 \%$ aged 55+). Information was a between subjects-factor, representing the nature of the verbal information provided to a participant. $50 \%$ of the participants received auditory distance information to enable them to locate a turning (as per current navigation systems), and 50\% received landmarks instead of distance within the auditory instruction. Manoeuvre was a within-subjects factor representing the eight target manoeuvres en-route, thereby enabling investigation of behavioural changes due to the variability of the characteristics of individual manoeuvres. Due to the constraints of driving an actual route with a real navigation system, it was not possible to randomise or balance the within-subjects factor, i.e. all participants completed the target manoeuvres in a set order. All trials took place mid morning or mid afternoon (i.e. off-peak traffic conditions).

\subsection{Dependent variables}

Dependent variables were captured that related to driver safety, navigation performance, workload, driver confidence and driver attitudes. Visual glance behaviour was measured via video capture in order to determine the number and duration of glances to the in-vehicle visual display during the $500 \mathrm{~m}$ approach to each manoeuvre. A percentage moving time metric was calculated as the total duration of the glances to the display whilst moving, divided by the total time spent moving during the approach to each manoeuvre.

Driving errors during the approach to each manoeuvre were assessed by a UK Driving Standards Agency Approved Driving Instructor who accompanied each participant during the trial (and was unaware of the exact nature of the independent variable manipulation). Errors were recorded as minor, serious or dangerous within six error categories as used in the UK Driving Examination: (1) use of mirrors and rear observation when signalling, changing direction and speed; (2) appropriate use of signals (indicators); (3) response to signs and signals including traffic signs, road markings, traffic lights, traffic controllers and other road users; (4) junctions, including speed of approach, observation, turning left or right and cutting corners; (5) positioning in normal driving and lane discipline; (6) awareness and planning. A minor error was one that was not in itself potentially dangerous unless it was habitual. A serious driving error was one where potential danger had occurred. A dangerous error was one involving actual danger to the driver/passenger or other road users.

All actual and near navigation errors were recorded. 'Near' navigation errors were those where a participant showed clear intention (e.g. a lane change or onset of indicators) to take 
an incorrect turn, even though they may have subsequently corrected this and completed the manoeuvre correctly.

Driver workload was assessed on completion of the experimental route using a slightly adapted version of the NASA RTLX (Hart \& Staveland, 1988) subjective workload assessment tool. This uses a set of rating scales to measure self-assessed driver workload. The adapted version (Fairclough, 1991) includes a scale to measure perceived driver distraction.

Driver confidence (after receiving each verbal instruction) was measured at approximately 450, 150 and 30 m from each target and non-target manoeuvre by application of a simple verbal subjective rating procedure which determined the driver's assessment of their confidence in relation to the extent they 'know where to turn and will be able to complete that manoeuvre successfully'. After completing each manoeuvre, participants gave an additional confidence rating to indicate their confidence that they had taken a correct turn.

Drivers' beliefs and evaluative attitudes, and their temporal changes, were assessed using a three part questionnaire based largely on five point agree-disagree Likert Scale responses. This was administered pre-trial, part-way through, and post-trial.

\subsection{Procedure}

On arrival, participants were introduced to the study, signed consent forms and completed part one of the questionnaire. After familiarising themselves with the vehicle controls, the participants completed a mixed-road familiarisation drive lasting approximately 25 minutes, without use of the navigation system.

An additional period of 20 minutes familiarisation and training with the navigation system took place. Participants then drove the trial route using the navigation system with simulated auditory output, giving the three pre- and one post-manoeuvre confidence ratings; they were occasionally prompted if necessary. During the approach to each manoeuvre, the nature and severity of any driving errors were recorded by the driving instructor, and navigation errors were recorded. Part two of the questionnaire was completed after completing four manoeuvres. The participant then navigated the rest of the test route and the modified NASA RTLX and part three of the questionnaire were completed before the participant was debriefed and paid. 


\section{Analysis and results}

\subsection{Visual behaviour}

Visual glance analysis was undertaken for the eight target manoeuvres of interest. Figure 1 shows the mean number of glances made to the display whilst the driver was moving, during the 500m approach to each of the eight target manoeuvres. A separate plot is shown for the between subjects factor of Information (ie whether they received landmarks or distance information to locate a turning). The other between subjects factor of Age is shown on each plot.

\section{$<$ INSERT FIGURE 1 ABOUT HERE $>$}

Figure 2 shows the mean duration of glances made to the display whilst the driver was moving, over the course of the eight target manoeuvres, for the between-subjects factors of Age and Information as above.

\section{$<$ INSERT FIGURE 2 ABOUT HERE $>$}

Figure 3 shows the percentage moving time metric (total time spent glancing to the display while moving, as a percentage of the time spent moving during the 500m approach) for the between-subjects factors of Age and Information as per the two previous figures.

\section{$<$ INSERT FIGURE 3 ABOUT HERE $>$}

The data for the within subjects factor of Manoeuvre showed non-sphericity, therefore a MANOVA was used to analyse the main effects of Age and Information. This analysed all of the target manoeuvres simultaneously (results are reported based on Wilks' Lambda). In addition, a univariate repeated measures analysis, with results adjusted for lack of sphericity by using the Huynh-Feldt Epsilon correction, was undertaken to investigate the impact of the within-subjects factor of Manoeuvre (ie to identify whether the manoeuvre itself had any impact on the dependent variable).

For the number of glances made to the display, there was no effect due to Age, but there was a significant effect of Information (ie whether participants used landmarks or distance information to locate a turning), $F(8,20)=5.986, p=.001$. There was no main effect of the repeated measure of Manoeuvre, and no interaction between Manoeuvre and Age, but there was an interaction between Manoeuvre and Information $F(6.320)=2.490, p=.022$. 
For the duration of glances made to the display, there was a significant effect of Age, $F(8,17)=2.792, p=.036$, but no effect due to Information (ie landmarks or distance information). There was also a main effect of the repeated measure of Manoeuvre, $F(4.905)=$ 6.369, $p<.001$, but no interaction between Manoeuvre and Age, or Manoeuvre and Information.

For the percentage moving time spent looking at the display, there was no effect due to Age, but there was a significant effect of Information (ie whether participants used landmarks or distance information to locate a turning), $F(8,20)=5.765, p=.001$. There was also a main effect of the repeated measure of Manoeuvre, $F(6.854)=3.524, p=.002$, no interaction between Manoeuvre and Age, but there was an interaction between Manoeuvre and Information, $F(6.854)=2.303, p=.029$.

\subsection{Driver confidence}

The driver confidence data consisted of four confidence ratings of low, medium or high (coded as 1, 2, 3 respectively) derived from three distinct points during the approach to, and one immediately after, each of the 33 manoeuvres on route. Figure 4 shows the change in mean subjective confidence level across all eight target manoeuvres, at each of the four confidence points. A separate plot is shown for the between subjects factor of Information (ie whether they received landmarks or distance information to locate a turning). The other between subjects factor of Age is shown on each plot. Note that these figures plot mean confidence ratings, not mean ranking data.

\section{$<$ INSERT FIGURE 4 ABOUT HERE $>$}

A Friedman non-parametric test for 3-related samples showed that for the $50 \%$ of participants using landmarks to locate forthcoming turnings, confidence increased on approach to the turn for both younger $\left(\mathrm{N}=8, \chi^{2}(3)=22.89, p<.001\right)$, and older $\left(\mathrm{N}=8, \chi^{2}(3)\right.$ $=8.01, p=.046$ ) drivers. There were no significant increases in confidence on approach to a manoeuvre for either the younger or older participants using distance to locate a turning.

In addition, when using landmarks to locate a turn, the older drivers were significantly more confident than the younger drivers after the Preview 2 point, at approximately $150 \mathrm{~m}$ from the turn $(\mathrm{U}=5.0, p=.003)$. 


\subsection{Driving errors}

In conjunction with the UK Driving Standards Agency Approved Driving Instructor, a coding scheme was devised whereby a score of one was assigned to each minor error a driver committed, a five to a serious error, and a 10 to a dangerous error. This was based on the pass/fail criteria for the UK driving test, plus the driver instructor assessment of habitual driving errors representing dangerous driving. Driving errors were aggregated for each participant over all eight target manoeuvres. Figure 5 shows the differences in the total driving error score for the younger and older age groups, according to whether they were using landmarks or distance to locate a turn. Due to the between-subjects design, each bar represents the total driving error score from $\mathrm{N}=8$ participants.

\section{$<$ INSERT FIGURE 5 ABOUT HERE $>$}

The figure above plots the total error scores, aggregated over all six individual error categories. A Mann-Whitney U test was used to compare the individual error category scores of the younger and older drivers, using either landmarks or distance to locate a turning. When participants used landmarks to locate a turn, there were no significant differences (in any of the error categories) in the scores of the younger and older drivers. A similar result occurred when using distance to locate a turn.

In contrast, for both younger drivers $(\mathrm{U}=68.5, p=.024)$, and older drivers $(\mathrm{U}=68.5, p=$ .024), a significantly lower error score in the 'indicator' category resulted from using landmarks (as opposed to distance) to locate a turning. In other error categories, there were trends for fewer errors with landmarks, but no significant differences.

\subsection{Navigation performance}

Actual or near navigation errors were aggregated for each participant over all eight target manoeuvres. Figure 6 shows the differences in navigation errors for the younger and older drivers, according to whether they were using landmarks or distance to locate a turn. As for the driving errors above, each bar represents data from $\mathrm{N}=8$ participants.

\section{$<$ INSERT FIGURE 6 ABOUT HERE $>$}

A Mann-Whitney U test was used to compare the navigation errors committed by the younger and older drivers, using either landmarks or distance to locate a turning When participants used landmarks to locate a turn, there were no significant differences in the 
navigation errors committed by the younger and older drivers, with a similar result occurred when using distance to locate a turn. However, for both younger $(U=4.0, p=.001)$, and older drivers ( $\mathrm{U}=12.0, p=.017$ ), significantly fewer navigation errors were committed when navigating the route using landmarks (as opposed to distance) to locate turns.

\subsection{Driver workload}

The data from the the NASA-RTLX constructs were combined with an equal weighting as per (Nygren, 1991). Using a univariate analysis, no significant differences were found in perceived total driver workload, due to either the information used to locate a turning, or the age category of the participants.

\subsection{Driver attitudes}

A summary of the main points arising from the 3-part questionnaire is presented, rather than a detailed set of results from all questions. Both younger and older drivers stated that using a navigation system was an easy way of finding their way in an unfamiliar area, they would be less likely to get lost, felt they drove safely when using it, and did not find driving more difficult as a result of using a system. There were no significant differences in attitudinal responses due to age. Perhaps most importantly from a product development perspective, older and younger drivers preferred using a navigation system to their usual means of navigating, and looked forward to using a navigation system again. This was particularly the case for those participants using landmarks to locate turns.

\section{Discussion}

The section below discusses the results arising directly from the trials. The conclusions that follow identify the implications for the design of in-vehicle navigation systems, and invehicle technology more generally, for the older driver.

\subsection{Visual glance behaviour}

When grouping the younger and older drivers together, using landmarks rather than distance information in the verbal instructions presented to participants resulted in an significant reduction in the number of glances made to the display during the approach to the target manoeuvres. There was a similar impact on both younger and older drivers, although Figure 1 shows a potential trend for older drivers to make fewer glances to the display than younger drivers when using distance to locate a turning. However, what is apparent from Figure 1 and highly statistically significant, is that the number of glances made to the in- 
vehicle display is much more impacted by the nature of the information provided to the driver, than by the age of the driver.

This reduction in the number of glances whilst using landmarks was also demonstrated by (Burnett, 1998) who found that emphasising landmarks (as opposed to distance) within a vehicle navigation system resulted in a reduction of glances during the approach to a manoeuvre from a mean of 5.0 to 1.6. A greater effect probably arose during the study by (Burnett, 1998) due to landmarks in that study also being represented on the visual display, as well as being contained within the verbal instructions.

Within the present study, when landmark information was not available to the driver, frequent glances were made to the distance countdown bar in order to locate a turn. Where landmark information was provided within turn-by-turn instructions, most participants made initial glances to the display when they received the first verbal instruction at about $500 \mathrm{~m}$ from the manoeuvre, and then looked again at the display during the final approach to a manoeuvre.

In contrast to the number of glances made, the analysis of the duration of the glances made to the in-vehicle display showed a clear effect due to the age of driver, and no difference according to the nature of the instructions received by the participants (Figure 2). The increase in the duration of visual fixations is consistent with the findings of (Labiale \& Galliano, 2002). It was expected that the independent variable of Information (ie landmarks or distance within the verbal instructions) would have no impact on the duration of glances, since the same visual information was displayed to the participants, independent of the information they received in their verbal instructions.

The percentage moving time metric was used to provide an overall figure for the time spent looking at the display on approach to each manoeuvre. It was a function of both the number of glances to the display whilst moving and the duration of those glances. Figure 3 again shows that there was a greater impact due to the information being used to locate a turning than that caused by the age differentiation of the participants (despite the clear difference in the glance durations, as shown in Figure 2). For both younger and older drivers, using landmarks as opposed to distance to locate a turning resulted in a reduction of about $40 \%$ in the percentage of time spent looking at the display. For this percentage moving time metric (which is used to represent the degree of visual distraction imposed on the driver), there was also a differential impact due to the individual target manoeuvre (which was influenced by Age, but was not influenced by the Information being used to locate a turning). It is difficult to interpret this finding, since there are a wide range of contextual factors which 
impact on the visual behaviour of a driver when using an in-vehicle display. These include the visibility of the manoeuvre, speed of traffic, drivers expectations (of where the next manoeuvre is likely to be) and the nature and location of the landmark. However, where there was a disproportionate increase in glances using distance information, this appeared to occur at those manoeuvres where turns were partially obscured on approach, and therefore difficult to locate via visual search of the environment without reference to a more visible landmark at or near the junction.

An interesting finding was that some older and younger participants made no glances to the display at particular manoeuvres when using landmarks to locate turns. This underlines the potential for developing in-vehicle HMIs for even complex tasks such as navigation, which place minimal reliance on an in-vehicle visual display.

In this study, the visual component of information provision to the driver was kept constant throughout the study in order to prevent a confounding of the display-induced visual demand on the driver. However the limitation of this was a resulting inconsistency of information display to those drivers using landmarks, since for those drivers, verbal landmark information was combined with visual distance representation. This is likely to have reduced the differential effect of the Information (landmarks vs distance) independent variable: a graphical representation of landmarks would have increased the ease of visually identifying the landmark, and further reduced the need to refer to distance on the visual display.

\subsection{Driver confidence}

The impact of Age and Information provision on driver confidence on approach to a manoeuvre is shown in Figure 4. In general, this figure shows that both younger and older drivers tended to be less confident during the initial approach to a manoeuvre when using landmarks to locate that turning. This figure also shows the significant increase in confidence on approach to a manoeuvre for both younger and older drivers when using landmarks to locate a turn, and the relatively stable levels confidence levels when using distance information.

The mean distance from the turning at which landmarks were visible was $210 \mathrm{~m}$, therefore at most manoeuvres the landmark being used to locate the turning was not visible directly after the Preview 1 message (at approximately $450 \mathrm{~m}$ from the manoeuvre) due to the road geometry, roadside furniture and other parked vehicles. At this point, referring to a landmark which was located at the manoeuvre does not help the driver actually locate the turning, hence the relatively low confidence levels for both younger and older drivers. 
For navigational confidence, the impact of landmarks did appear to vary according to age, as when using landmarks, the older drivers were significantly more confident than the younger drivers at the Preview 2 point (at approximately $150 \mathrm{~m}$ from the manoeuvre). However, this needs to be interpreted in the light of the comments above. Several authors (eg (Alm et al., 1992) have found landmarks to improve driver confidence regarding where to turn. However the present study additionally investigated changes in confidence over the approach to a manoeuvre. In addition, (Burns, 1997) has suggested that landmarks can particularly boost the confidence of older drivers, and this appears to be partly supported by the results of this study.

\subsection{Driving errors}

The impact of Age and Information provision on driving errors committed during the approach to a manoeuvre is shown in Figure 5. The incorporation of landmarks had clear benefits for both the younger and older drivers, by significantly reducing inappropriate use of the direction indicators. This is consistent with other studies that have looked at the effect on driving errors of including landmarks in navigation instructions (Bengler et al., 1994; Philips, 1999). In addition, landmarks appeared to reduce errors related to the use of mirrors and rear observation when signalling, changing direction and speed control, although this result was not statistically significant. Driving errors therefore appeared to be reduced by the incorporation of landmarks within navigation instructions, irrespective of the age category of the driver.

\subsection{Navigation errors}

The driving errors (intended or actual) committed by the younger and older drivers, using landmarks or distance information, are shown in Figure 6. There was no difference in the navigation performance of younger and older drivers. The clear finding was that both younger and older drivers benefited from the incorporation of landmarks in navigation instructions and made fewer (actual or near) navigation errors than those using distance information to locate a turn. The potential navigation benefit of landmarks mirrors the results of other studies including (Alm et al., 1992) and (Bengler et al., 1994).

\subsection{Driver workload}

The results for perceived driver workload failed to detect any differences according to either the age of the driver, or whether drivers were using landmarks or distance information to locate a turn. Early navigation studies (Alm et al., 1992) have shown that drivers' mental 
workload was lower when including landmarks in navigation instructions, and the NASARTLX has been successfully employed within driving research to demonstrate effects due to a range of independent variables such as form or modality of information presentation (Lee, Caven, Haake, \& Brown, 2001). It is likely that this measure was insufficiently sensitive to the intermittent impact on driver demand arising from the use, or non-use of landmarks, which were incorporated in the verbal messages only. In addition, it was necessary to ensure face validity throughout the trial, and therefore a manipulation of the independent variable (and therefore expected differences in workload) only occurred at those manoeuvres where landmarks were present, whereas the NASA-RTLX was completed at the end of the trial having completed all target and non-target manoeuvres.

\subsection{Driver Attitudes}

A detailed discussion of the driver attitudes is not presented, since the main focus of this article is on the real-time behavioural implications of incorporating landmarks within invehicle HMIs. Driver attitudes were fairly consistent between the younger and older driver groups. They were positive towards the potential benefits of a navigation system, the concept of using landmarks within the instructions they received, and the design implementation that was employed within the trial. This confirms the widely held belief that if technology is designed appropriately, it is readily accepted by the older population.

\subsection{Limitations to the study}

There were several potential limitations to the study. As with many road-based trials, there was a relative lack of control over potentially confounding factors such as the context associated with each target manoeuvre, and the influence of other traffic. In addition, although based on recognised driving error categories and severities, the reliability of the driving error score metric has not been tested. Finally, due to the relatively challenging nature of the trial, it proved difficult to recruit older participants, and hence a lower bound of only 55 was used to define this age group.

\section{Summary and conclusions}

The main findings from this study were that both younger and older drivers benefited significantly from the incorporation of landmarks in the turn-by-turn instructions provided by a navigation system. Both age groups made fewer glances to the display, spent less overall time looking at the display on approach to a manoeuvre, and committed fewer driving and 
navigation errors. Landmarks, when visible to an approaching driver, appeared to particularly improve the confidence of older drivers.

However, during the early stages of an approach to a manoeuvre when a landmark at the turn may not be visible, distance to turn resulted in the greatest driver confidence for both younger and older drivers.

The only other significant difference of note between the older and younger drivers was the increased glance durations of the older drivers, being approximately $10 \%$ higher than those of the younger drivers as shown in Figure 2, although in terms of the total time spent attending to the information display, these longer glances tended to be offset by fewer glances being made.

Navigation systems are likely to be used by older drivers due to the relative wealth of many of this group (Foresight, 2000), and the potential benefits that these systems offer. The design recommendations regarding future navigation systems that may be used by older drivers are clear -they should not rely on distance-to-turn information to locate forthcoming manoeuvres. Prominent landmarks at or near manoeuvres should be used to provide visual confirmation of the location of turns, and help indicate the required direction of travel. However, distance information should not be excluded totally, since it provides initial confidence on approach to a manoeuvre when a landmark is not yet visible. Traffic lights are particularly suitable landmarks since they are ideally located at manoeuvres, familiar, and highly visible during the day and at night.

There are some wider implications for the user-centred design of new in-vehicle technology that may be used by an older age group. Systems will be as useful for older drivers, and received as positively, if they meet a perceived need and are designed effectively. However, due to the tendency of older drivers to make longer glances when assimilating information presented visually in a vehicle, auditory information presentation offers particular safety benefits to this group of drivers. If visual displays are used, then particular care should be taken to (1) avoid complex visual displays, and (2) to test the visual demand characteristics using techniques such as visual occlusion as described in emerging international standards.

In conclusion, the study has shown how the application of user-centred design principles for new technology is a fundamental prerequisite for designing safe and effective new invehicle technology. Consistent with the philosophy of inclusive design (and as highlighted by Pauzie, 2003), the recommendations that emerge will benefit all drivers not just those which are older. 


\section{Acknowledgments}

Support for this study was provided by an EPSRC research grant from the UK

Government. The authors also wish to acknowledge the valuable assistance of Derek Brutnell, Jason Duffield, and Sebastian Paszkowicz. 


\section{References}

Allen, G. L. (1999). Cognitive Abilities in the Service of Wayfinding: A Functional Approach. Professional Geographer, 51(4), 554-561.

Allerton, J. E. (2000). Tailoring Vehicle Navigation Systems to Individual and Environmental Factors - a A Road Based Study. Unpublished Unpublished MSc thesis, Loughborough University, Loughborough.

Alm, H., Nilsson, L., Jarmark, S., Savelid, J., \& Hennings, U. (1992). The effects of landmark presentation on driver performance and uncertainty in a navigation task - a field study (No. S/IT-4): (Swedish Prometheus, Tech. Rep. No. S/IT-4). Linköping, Sweden: VTI.

Bengler, K., Haller, R., \& Zimmer, A. (1994). Experimental optimisation of route guidance information using context information. Paper presented at the First World Congress on Applications of Transport and Intelligent Vehicle Highway Systems, Paris, France.

Boeoek, A., \& Gaerling, T. (1978). Processing of information about location during locomotion: Effects of a concurrent task and locomotion patterns.

Burnett, G. E. (1998). "Turn right at the King's Head": Drivers' requirements for route guidance information. Unpublished Unpublished $\mathrm{PhD}$ thesis, Loughborough University, UK.

Burnett, G. E. (2000). 'Turn right at the traffic lights': The requirement for landmarks in vehicle navigation systems. Journal of Navigation, 53(3), 499-510.

Burnett, G. E., Smith, D., \& May, A. J. (2001). Supporting the navigation task: characteristics of 'good' landmarks. Paper presented at the Contemporary Ergonomics 2001: Proceedings of the Annual Conference of the Ergonomics Society.

Burns, P. C. (1997). Navigation and the older driver. Unpublished Unpublished PhD thesis, Loughborough University, Loughborough, UK.

Burns, P. C. (1998). Wayfinding errors while driving. Journal of Environmental Psychology, 18, 209-217.

Dingus, T. Q., Hulse, M. C., Mollenhauer, M. A., Fleischman, R. N., McGehee, D. V., \& Manakkal, N. (1997). Effects of age, system experience, and navigation technique on driving with an advanced traveler information system. Human factors, 39(2), 177199.

Fairclough, S. H. (1991). Adapting the TLX to Measure Driver Mental Workload (DRIVE Project V1017 (BERTIE) No. Report no. 71). Loughborough, UK: HUSAT Research Institute.

Fine, B. J., \& Kobrick, J. L. (1983). Individual differences in distance estimation: Comparison of judgments in the field with those from projected slides of the same scenes. Perceptual-and-Motor-Skills, 57(1), 3-14.

Foresight. (2000). Ageing Population Panel - Finance Taskforce: Department of Trade and Industry.

Goodman, J., Brewster, S. A., \& Gray, P. (2005). How can we best use landmarks to support older people in navigation? Behaviour \& Information Technology, 24(1), 3-20.

Green, P., Hoekstra, E., Williams, M., Wen, C., \& George, K. (1993). Examination of a videotape-based method to evaluate the usability of route guidance and traffic information systems (Final No. UMTRI-93-31): (Tech. Rep. No. UMTRI-93-31). Ann Arbor, MI: University of Michigan Transportation Research Institute.

Green, P., Levison, W., Paelke, G., \& Serafin, C. (1995). Preliminary human factors guidelines for driver information systems (No. UMTRI Technical Report No. 93-21). Michigan: Ann Arbor: University of Michigan Transportation Research Institute. 
Hart, S. G., \& Staveland, L. E. (1988). Development of NASA-TLX (Task Load Index): results of empirical and theoretical research. In P. A. Hancock \& N. Meshkati (Eds.), Human Mental Workload (pp. 139-183). Amsterdam: North-Holland.

Jackson, P. G. (1998). In search of better route guidance instructions. Ergonomics, 41(7), 1000-1013.

Kaplan, S. (1976). Adaption, structure and knowledge. In G. T. Moore, Golledge, R.G. (Ed.), Environmental Knowing: theories, research and methods (pp. 32-45). Stroudsburg: Dowden, Hutchinson and Ross Inc.

King, G. F. (1986). Driver performance in highway navigation tasks. Transportation research record(1093), 1-11.

Kirasic, K. C. (2000). Ageing and spatial behaviour in the elderly adult. In R. Kitchin \& S. Freundschuh (Eds.), Cognitive Mapping: Past, present and future (pp. 166-178). London: Routledge.

Labiale, G., \& Galliano, M. (2002). Effects of Complexity of In-Car Information on Visual Fixations and Driving Performance. In D. d. Waard, K. A. Brookhuis, J. Moraal \& A. Toffetti (Eds.), Human Factors in Transportation, Communication, Health, and the Workplace (pp. 147 - 154). Maastricht, The Netherlands: Shaker Publishing.

Lee, J. D., Caven, B., Haake, S., \& Brown, T. L. (2001). Speech-Based Interaction with InVehicle Computers: The Effect of Speech-Based E-Mail on Drivers' Attention to the Roadway. Human Factors, 43(4), 631-640.

Lynch, K. (1960). The Image of the City. Cambridge, Mass: MIT Press.

Mourant, R. R., Tsai, F. J., Al-Shihabi, T., \& Jaeger, B. K. (2001). Measuring DividedAttention Capability of Young and Older Drivers. Traffic Safety 2001: Americans with Disabilities Act; Driver and Vehicle Modeling; Situation Awareness; Licensing; Driver Behavior; Enforcement; Trucks; and Motorcycles by the Transportation Research Board, National Research Council, Washington, D.C. National Academy Press, Washington, D.C., Transportation Research Record No.1779, 40 - 45.

Nygren, T. E. (1991). Psychometric properties of subjective workload measurement techniques: Implications for their use in the assessment of perceived mental workload. Human Factors, 33, 17-31.

Passini, R. (1984). Spatial representations, a wayfinding perspective. Journal of environmental psychology, 4(153-164).

Pauzie, A. (2003). Ageing Population and Ergonomics of Innovative Communicating Technologies in Driving. Recherche Transports Securite, 81, 203 - 212.

Philips, B. H. (1999, September 27-October 1, 1999). The Role of Landmark Information in Intelligent Navigation Displays. Paper presented at the Houston... We Have a Solution! , Proceedings of the Human Factors and Ergonomics Society 43rd Annual Meeting.

Streeter, L. A., Vitello, D. (1986). A profile of drivers' map-reading abilities. Human factors, 28(2), 223-239.

Tom, A., \& Denis, M. (2003). Referring to Landmark or Street Information in Route Directions: What Difference Does It Make? In W. Kuhn, M. F. Worboys \& S. Timpf (Eds.), COSIT 2003 Lecture Notes in Computer Science 2825 (pp. 362-374). Berlin: Springer-Verlag.

Ward, S. L., Newcombe, N., Overton, W.F. (1986). Turn left at the church or 3 miles north a study of direction giving and sex differences. Behaviour and environment, 18(2), 192-213.

Widlroither, H., Hagenmeyer, L., Breker, S., \& Panou, M. (2003). On Designing Automotive HMIs for Elderly Drivers: The AGILE Initiative. In C. Stephanidis \& J. Jacko (Eds.), Human-Computer Interaction: Theory and Practice (Part II) (pp. 323 - 327).

Mahwah, New Jersey: Lawrence Erlbaum Associates. 
Wierwille, W. W., Antin, J. F., Dingus, T. A., \& Hulse, M. C. (1989). Visual attentional demand of an in-car navigation display system. In A. G. Gale (Ed.), Vision in vehicles II (pp. 307-316): London: Elsevier Science. 


\section{List of tables and figures}

Table 1 . The criteria used to define a 'target manoeuvre'

1 A left or right turn off the main route

2 An effective landmark that could be used to identify the turn

3 Other potential turns nearby (i.e. a requirement for information to precisely locate the manoeuvre)

$4 \quad$ Preferably at least a $500 \mathrm{~m}$ approach to allow for the presentation of three auditory messages

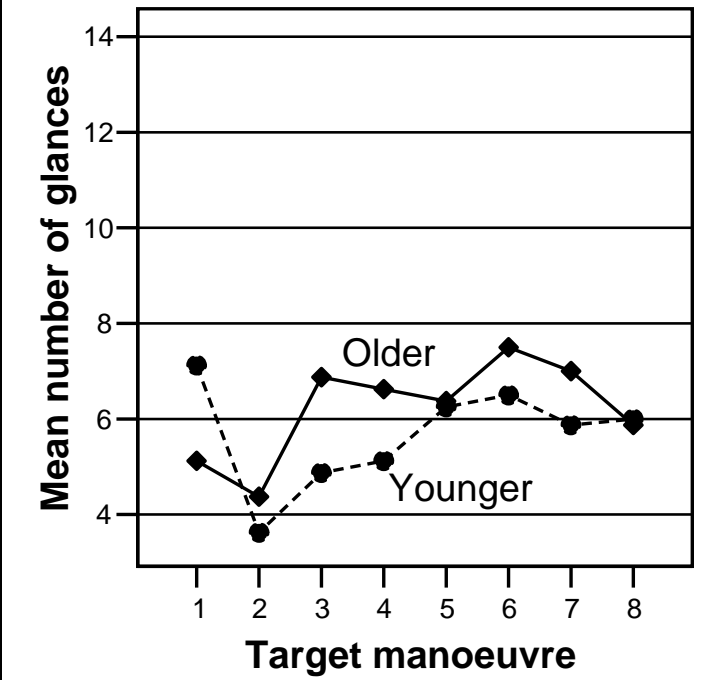

Using landmarks to locate a turning

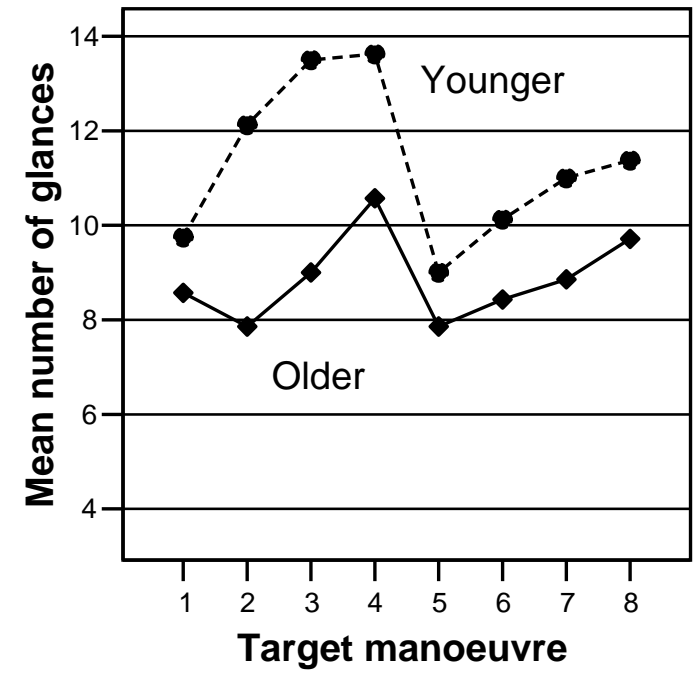

Using distance to locate a turning

Figure 1. The number of glances made to the display during approach to a manoeuvre, according to Age and Information. 


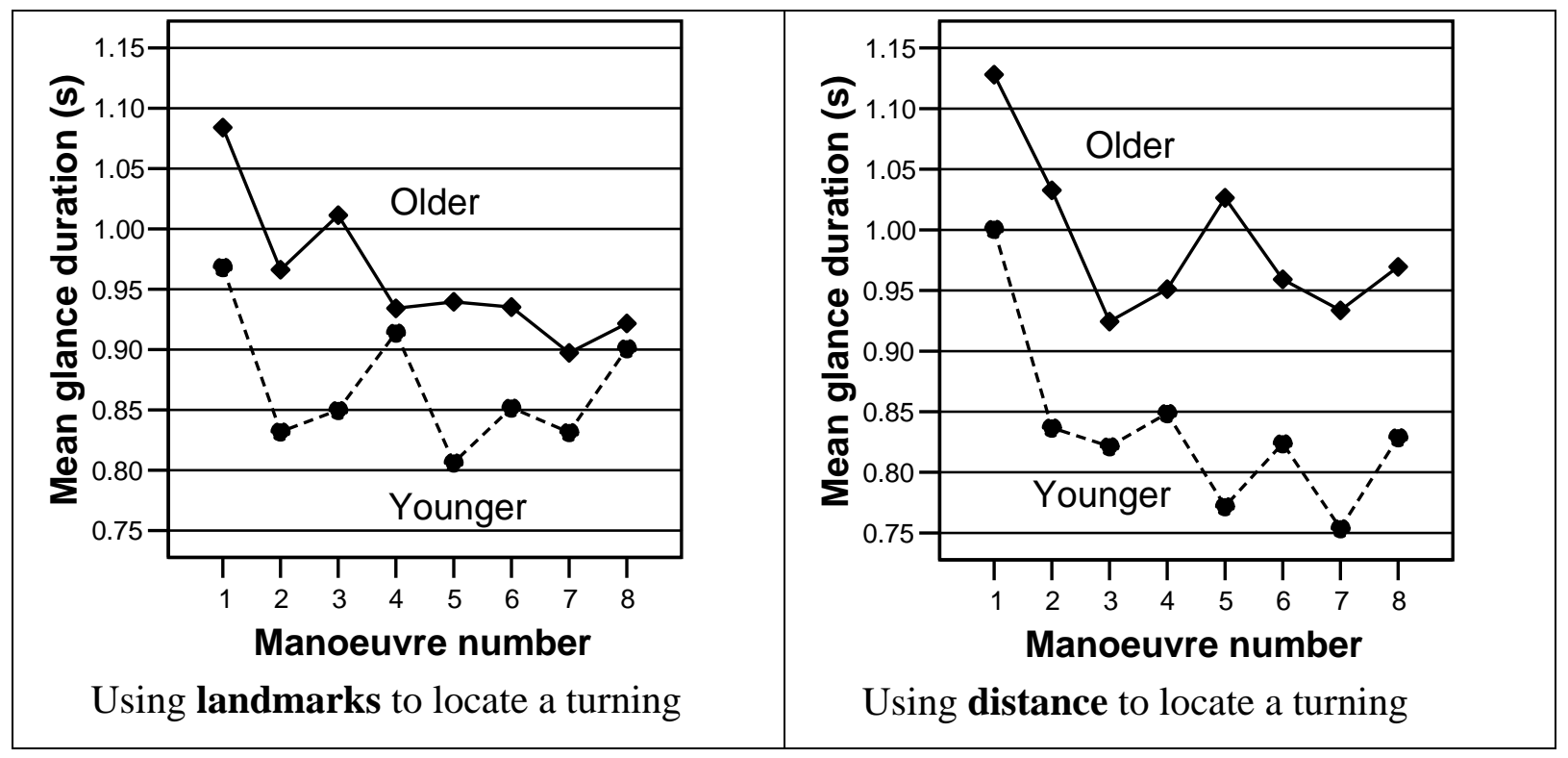

Figure 2. The duration of glances made to the display during approach to a manoeuvre, according to Age and Information

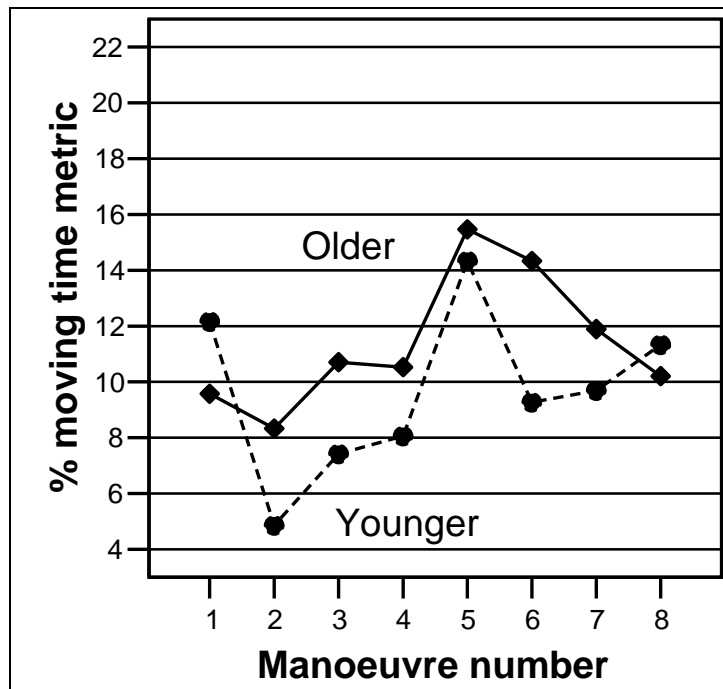

Using landmarks to locate a turning

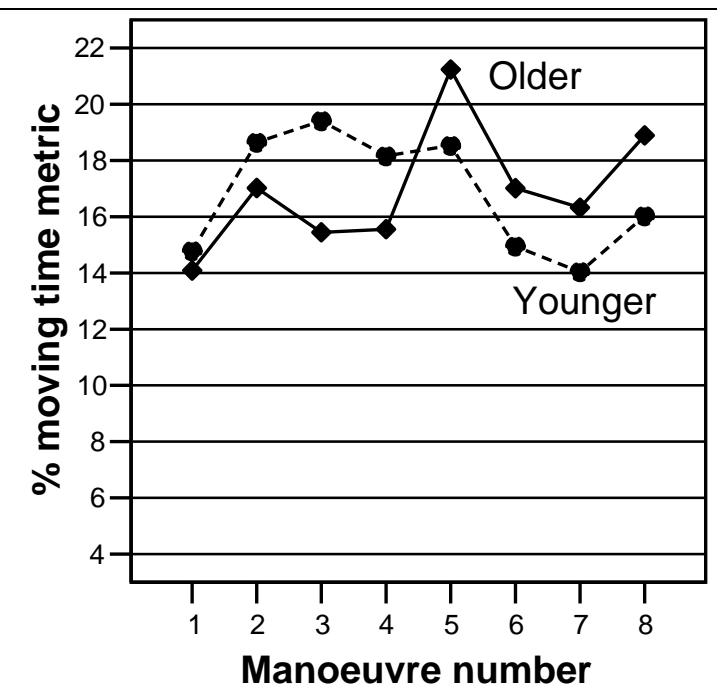

Using distance to locate a turning

Figure 3. The percentage moving time spent glancing to the display during approach to a manoeuvre, according to Age and Information 


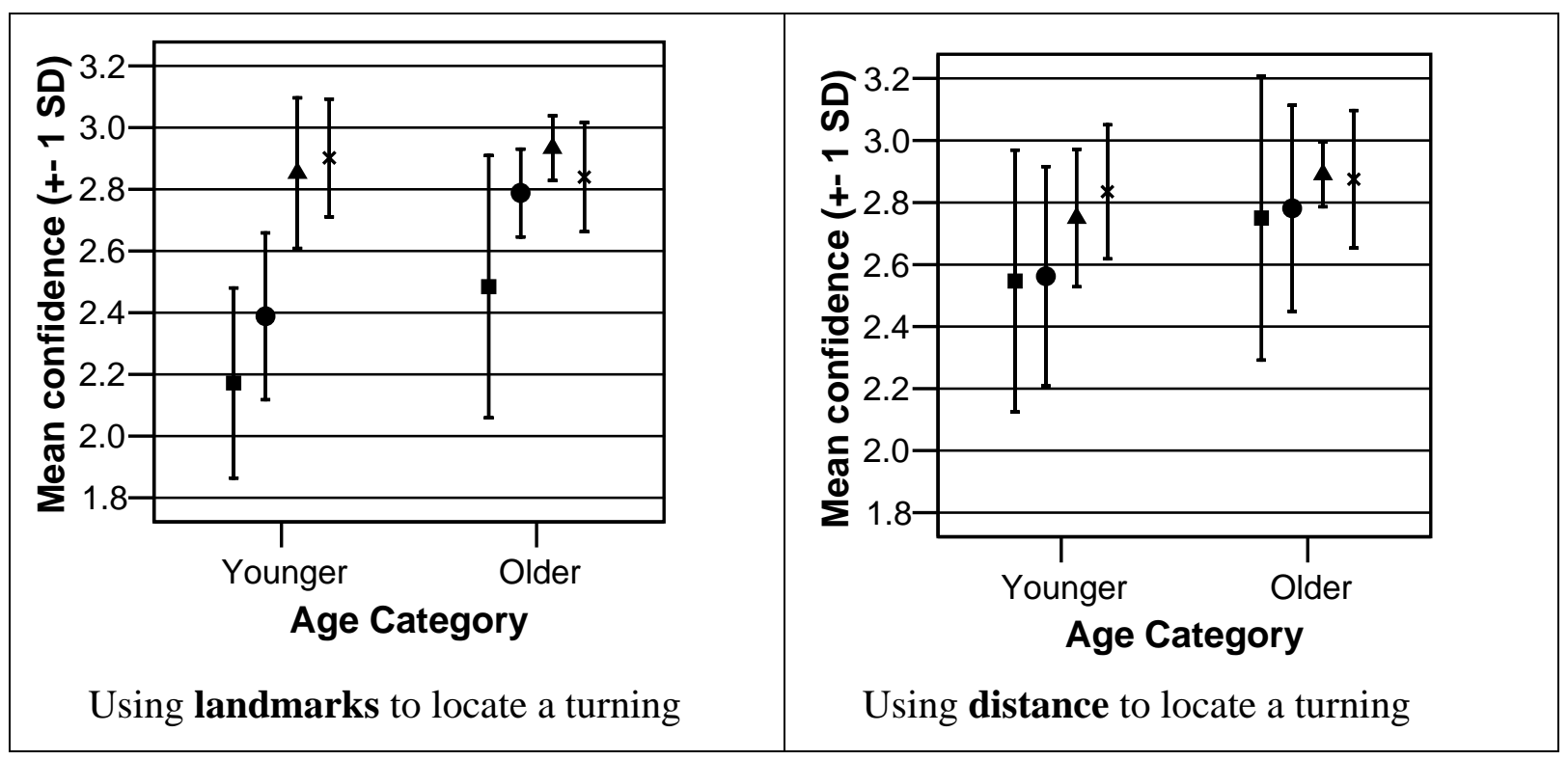

Figure 4. The changes in driver confidence on approach to a manoeuvre, according to Age and Information. Each bar within a cluster represents driver confidence at the Preview 1, Preview 2, Final and Post manoeuvre points. 


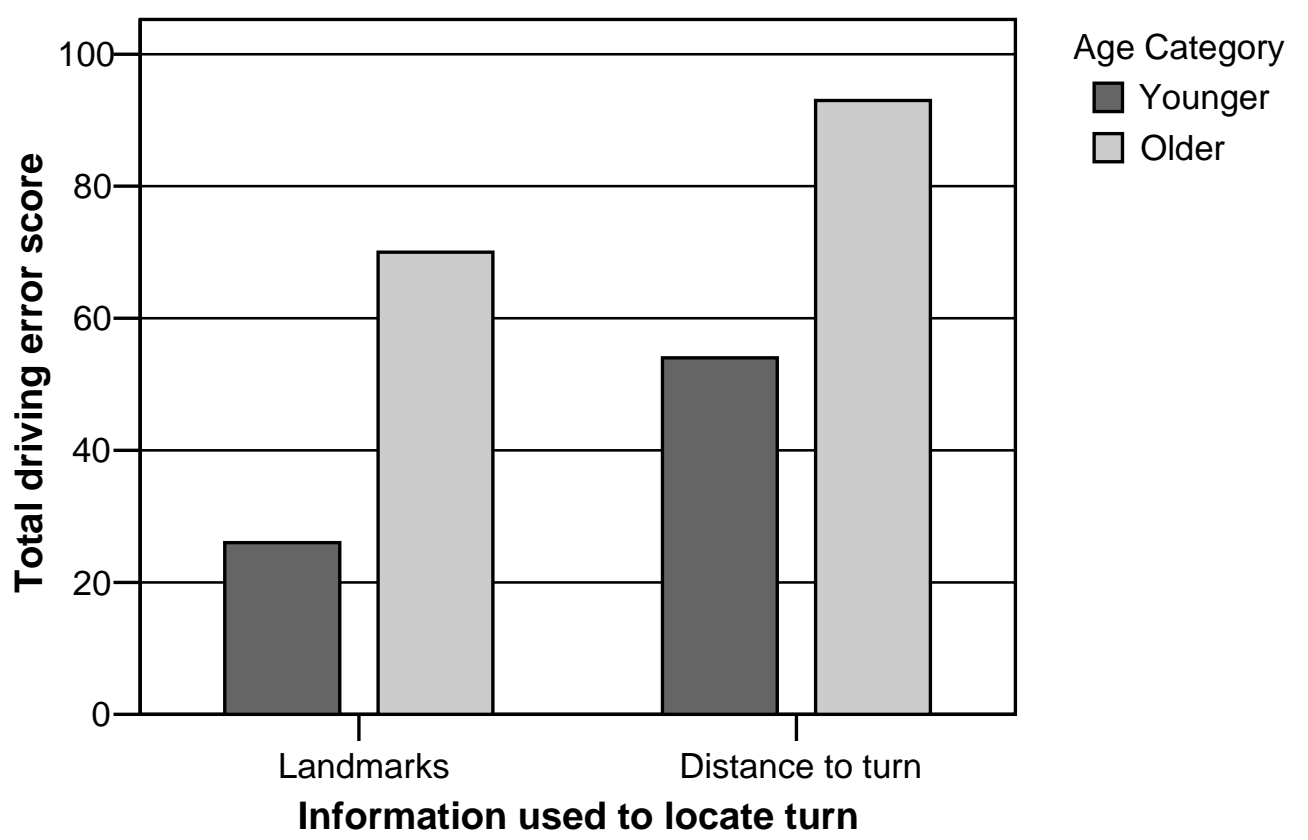

Figure 5. The total driving error score per participant group, according to Age and Information

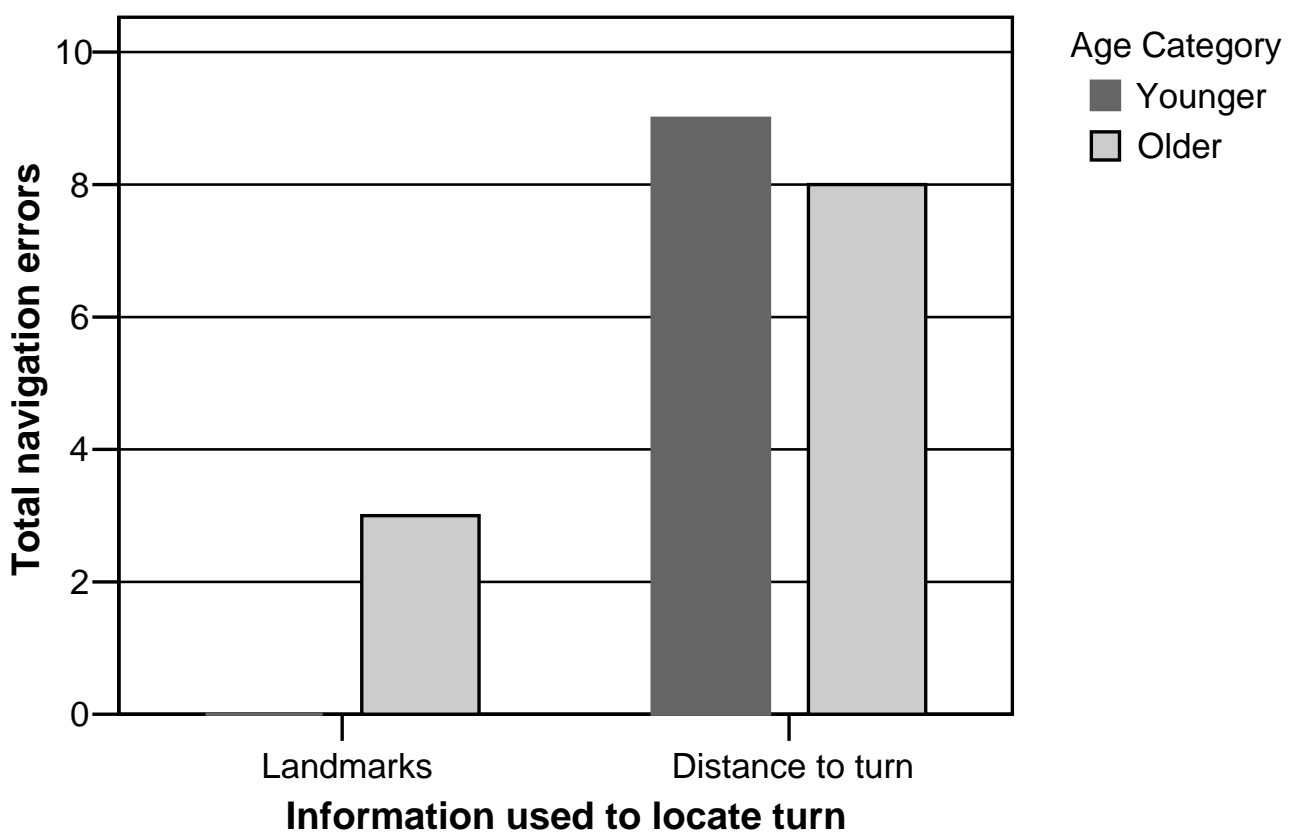

Figure 6. The total number of navigation errors made by each participant group, according to Age and Information 